\title{
Protection of Aluminium Metal in 0.5 M HCl Environment by Mature Arecanut Seed Extracts: A Comparative Study by Chemical, Electrochemical and Surface Probe Screening Techniques
}

\author{
Narasimha Raghavendra and Jathi Ishwara Bhat* \\ Department of Chemistry, Mangalore University, Mangalagangotri, \\ Karnataka 574199, India \\ ${ }^{*}$ Corresponding author: bhatij@yahoo.com
}

Published online: 25 April 2018

To cite this article: Raghavendra, N. \& Bhat, J. I. (2018). Protection of aluminium metal in $0.5 \mathrm{M} \mathrm{HCl}$ environment by mature arecanut seed extracts: A comparative study by chemical, electrochemical and surface probe screening techniques. J. Phys. Sci., 29(1), 77-99, https://doi.org/10.21315/jps2018.29.1.6

To link to this article: https://doi.org/10.21315/jps2018.29.1.6

\begin{abstract}
The corrosion inhibition behaviour of ethyl acetate extract from mature arecanut seed (EEMAS) and water extract from mature arecanut seed (WEMAS) on aluminium in $0.5 \mathrm{M}$ hydrochloric acid ( $\mathrm{HCl}$ ) environment was thoroughly investigated by employing gravimetric (weight loss), electrochemical (Tafel plot and AC impedance) and surface probe (SEM and AFM) techniques. From the gravimetric technique, it was observed that, the superior inhibition property was ensured at the concentration of $12 \mathrm{gl}^{-1}$ of plant extracts. The chemical or physical nature of the film formed by plant extracts (both EEMAS and WEMAS) was further inspected based on kinetic and thermodynamic parameters. According to Tafel plot studies, the corrosion current value decreases appreciably with an increase in the plant product concentration, which is an indication of the reduction in the corrosion rate. An increase in the charge transfer resistance values with the addition of plant extract constituents to the corrosive medium was clearly observed from AC impedance spectroscopy technique. Surface characterisation of target metals by scanning electron microscopy (SEM) and atomic force microscopy (AFM) techniques as a function of contact time in a corrosive medium $(0.5 \mathrm{M} \mathrm{HCl})$ noticeably gives clue about the protective role of plant extracts on the metal (aluminium) surface. The order of protection efficiency obtained from all techniques was found to be WEMAS $>$ EEMAS.
\end{abstract}

Keywords: Mature arecanut seed, weight loss, Tafel plot, AC impedance spectroscopy, scanning electron microscopy 


\section{INTRODUCTION}

Aggressive acid solutions, including hydrochloric acid $(\mathrm{HCl})$, are widely used for elimination of unnecessary rust and scales in chemical, engineering and industrial processes. Due to the aggressive nature of acid solutions, particularly $\mathrm{HCl}$, these processes habitually lead to the ample dissolution of the central aluminium metal. Prevention of dissolution rate of aluminium material is a major tasks for chemical and other industries. For this reason, inhibitors are generally used to control the acid consumption and aluminium metal dissolution. ${ }^{1-7}$

Corrosion inhibitors are substances that appreciably suppress the rate of corrosion of reactive metals via surface modification by adsorption mode. In practice, copious organic, non-organic and polymeric species were used as effective corrosion inhibitors in defending aluminium metal surfaces against $\mathrm{HCl}$ environment. The performance of these species as a corrosion inhibitor is mainly related to their molecular, chemical structure, and greater affinity to be adsorbed on the surface of the metals. But, majority of synthesised species (organic, non-organic and polymeric) are costly and lethal in nature, which hinder their utilisation for corrosion inhibition process. This has necessitated the seek for alternative corrosion inhibitors that are relatively inexpensive and environmentally friendly. Therefore, corrosion scientists focused on plant-based products due to their ecological and environment-friendly characteristics. In addition, they are easily available, biodegradable, cost effective, and bear adsorption centre elements such as nitrogen, sulphur, phosphorus and oxygen in their alkaloids and polyphenols moieties. Hence, many parts of plant products such as husk, leaf and seed extract constituents are broadly used as effective anti-corrosive agents in corrosive systems with less or zero environmental effect. Therefore, these constituents are called green corrosion inhibitors..$^{8-15}$

Mature arecanut seed is one of the greenest products possessing hetero-atoms in their alkaloids, fibre, polysaccharides, fat and polyphenols contents. It is known that different types of arecanut contain different chemicals with different concentrations. Mature arecanut seed contains a high concentration of polyphenols when compared to dry arecanut seed (low compared with tender arecanut seed) and low concentration of alkaloids when compared to dry arecanut seed (high compared with tender arecanut seed). The major polyphenolic compounds present in the mature arecanut seed are leucocyanidin, rutin, catechin, procyanidin $B_{1}$, epicatechin and gallic acid. The main constituents of alkaloids are arecoline, guvacoline, guvacine, arecaidine, arecolidine and isoguvacine. ${ }^{16-22}$ To our best knowledge, literature on the EEMAS and WEMAS constituents as corrosion inhibitors for aluminium metal in $0.5 \mathrm{M} \mathrm{HCl}$ environment is scant. Therefore, the intention of the current study is to scrutinise the inhibiting behaviour of EEMAS 
and WEMAS constituents for the corrosion of aluminium metal in $100 \mathrm{ml}$ of 0.5 M HCL environment. Further, morphology of electrode surfaces was analysed by SEM and atomic force microscopy (AFM) techniques.

\section{EXPERIMENTAL}

\subsection{Materials}

Material used for the present study is aluminium (A-63400), its nominal composition in weight percentage is clearly presented in Table $1 .{ }^{23}$

Table 1: Chemical composition of A-63400 type aluminium specimen.

\begin{tabular}{cccccccccc}
\hline Element & $\mathrm{Mg}$ & $\mathrm{Cu}$ & $\mathrm{Fe}$ & $\mathrm{Si}$ & $\mathrm{Zn}$ & $\mathrm{Mn}$ & $\mathrm{Tl}$ & $\mathrm{Cr}$ & $\mathrm{Al}$ \\
\hline $\mathrm{wt} \%$ & $0.4-0.9$ & 0.1 & 0.6 & $0.3-0.7$ & 0.2 & 0.3 & 0.1 & 0.2 & $\begin{array}{c}\text { Remainder } \\
(96.9 \%-97.8 \%)\end{array}$ \\
\hline
\end{tabular}

\subsection{Test Solution Preparation}

An amount of $0.5 \mathrm{M} \mathrm{HCl}$ solution was prepared by dilution of an analytical grade HCL, purchased from Merck, using doubly distilled water.

\subsection{Preparation of Inhibitors}

EEMAS and WEMAS inhibitors were prepared by boiling $200 \mathrm{~g}$ of fresh mature arecanut seeds in a Soxhlet apparatus for $5 \mathrm{~h}$ in $400 \mathrm{ml}$ of ethyl acetate and water separately. Resulting solutions were filtered and stored in refrigerator to avoid the side chemical, physical and biological reactions. Four different concentrations namely, $2 \mathrm{~g} \mathrm{l}^{-1}, 4 \mathrm{~g} \mathrm{l}^{-1}, 8 \mathrm{~g} \mathrm{l}^{-1}$ and $12 \mathrm{~g} \mathrm{l}^{-1}$ were prepared to study their influence on the metal surface.

\subsection{Weight Loss Method}

The wiped metal (aluminium) was immersed in $100 \mathrm{ml}$ of $0.5 \mathrm{M} \mathrm{HCl}$ solution without and with EEMAS and WEMAS at laboratory temperature $(303 \mathrm{~K})$. The working electrodes (aluminium metals) were removed from the corrosive system after 1, 2, 3, 4, 5 and $10 \mathrm{~h}$ duration. The removed metals were washed with tap water, rinsed with distilled water, then washed with acetone and finally dried. The discrepancy in the weight was taken as loss of weight of metal. The procedure was repeated until the constant value was obtained. Tests were also performed at $308 \mathrm{~K}, 313 \mathrm{~K}, 318 \mathrm{~K}$ and $323 \mathrm{~K}$ temperatures. From this method, protection efficiency $\left(\eta_{\mathrm{w}}\right)$ and corrosion rate $\left(v_{\text {corr }}\right)$ were determined as described earlier. ${ }^{24,25}$ 


\subsection{Electrochemical Studies}

Tafel plot and AC impedance spectroscopy studies were performed using CHI660C workstation. Potentiodynamic polarisation (Tafel plot) measurements were carried out with three electrodes: platinum rod as auxiliary electrode, aluminium metal pieces as working electrode, and saturated calomel rod as a reference electrode. Tafel curves without and with of plant extracts in $0.5 \mathrm{M} \mathrm{HCl}$ solution was obtained by applying potential from $-200 \mathrm{mV}$ to $+200 \mathrm{mV}$ vs. open circuit potential (OCP) with scan rate $0.01 \mathrm{~V} \mathrm{~s}^{-1}$. Impedance measurements were carried out in the frequency range from $1,00,000 \mathrm{~Hz}$ to $1 \mathrm{~Hz}$ with an amplitude of 0.01 (V) peak-topeak using AC signals at open circuit potential. The impedance diagrams obtained were presented as Nyquist plots.

\subsection{FTIR Characterisation}

The presence of functional groups in EEMAS and WEMAS responsible for corrosion inhibition process was confirmed by Fourier transform infrared (FTIR) spectroscopy technique (wave number range: $4000-400 \mathrm{~cm}^{-1}$ ).

\subsection{Surface Screening}

Surface morphologies of the unprotected and protected (with the addition of plant extracts) aluminium metal surface in $0.5 \mathrm{M} \mathrm{HCl}$ solution for effective $2 \mathrm{~h}$ of duration were examined using SEM and AFM techniques.

\section{RESULTS AND DISCUSSION}

\subsection{Weight Loss (Gravimetric) Studies}

Weight loss method is a useful technique for determination of protection efficiency and corrosion rate values. Corrosion behaviour of aluminium in $0.5 \mathrm{M}$ $\mathrm{HCl}$ environment in the absence and presence of plant extracts was studied in detail by using this technique. The parameters obtained by this technique were presented in Tables 2 and 3. Inspection of Tables 2 and 3 reveals that the rate of corrosion of metal (aluminium) was highly hindered with the introduction of plant extracts to the corrosive system as compared with bare solution, which indicates that plant extract constituents exerting inhibiting action on the metals by strongly adsorbing molecules on the surface of the metal. However, dissolution enhanced gradually with increasing temperature of the system is an indication of desorption of plant molecules from the active metal sites. As a result, greater active metal surface area is exposed to aqueous $\mathrm{HCl}$ solution causing enhanced corrosion rate. 
When the studies were carried out with different time intervals, it was observed that, corrosion inhibition efficiency decreases with increase in time from $1 \mathrm{~h}$ to $10 \mathrm{~h}$, which is due to high consumption of inhibitor molecules in the aggressive hydrochloric acid system with a longer immersion period.

Table 2: Gravimetric parameters at laboratory temperature (303 K).

\begin{tabular}{|c|c|c|c|c|c|c|c|}
\hline \multirow{2}{*}{$\begin{array}{l}\text { Time } \\
\text { (h) }\end{array}$} & \multirow{2}{*}{$\begin{array}{c}\text { Concentration } \\
\left(\mathrm{g} \mathrm{l}^{-1}\right)\end{array}$} & \multicolumn{2}{|c|}{$\left(v_{\text {corr }}\right)^{-4}(\mathrm{mpy})$} & \multicolumn{2}{|c|}{$\begin{array}{c}\text { Surface coverage } \\
(\theta)\end{array}$} & \multicolumn{2}{|c|}{$\begin{array}{l}\text { Protection efficiency } \\
\qquad\left(\eta_{\mathrm{w}}\right)\end{array}$} \\
\hline & & EEMAS & WEMAS & EEMAS & WEMAS & EEMAS & WEMAS \\
\hline \multirow[t]{5}{*}{1} & Blank & 8.699 & 8.699 & - & - & - & - \\
\hline & 2 & 2.416 & 1.933 & 0.722 & 0.777 & 72.222 & 77.777 \\
\hline & 4 & 1.933 & 1.449 & 0.777 & 0.833 & 77.777 & 83.333 \\
\hline & 8 & 1.449 & 0.966 & 0.833 & 0.888 & 83.333 & 88.888 \\
\hline & 12 & 0.966 & 0.483 & 0.888 & 0.944 & 88.888 & 94.444 \\
\hline \multirow[t]{5}{*}{2} & Blank & 11.116 & 11.116 & - & - & - & - \\
\hline & 2 & 3.624 & 3.141 & 0.673 & 0.717 & 67.391 & 71.739 \\
\hline & 4 & 2.658 & 1.933 & 0.760 & 0.826 & 76.086 & 82.608 \\
\hline & 8 & 1.933 & 1.449 & 0.826 & 0.869 & 82.608 & 86.956 \\
\hline & 12 & 1.449 & 1.208 & 0.869 & 0.891 & 86.956 & 89.130 \\
\hline \multirow[t]{5}{*}{3} & Blank & 16.110 & 16.110 & - & - & - & - \\
\hline & 2 & 5.316 & 4.833 & 0.670 & 0.700 & 67.000 & 70.000 \\
\hline & 4 & 4.027 & 3.544 & 0.750 & 0.780 & 75.000 & 78.000 \\
\hline & 8 & 3.222 & 2.738 & 0.800 & 0.830 & 80.000 & 83.000 \\
\hline & 12 & 2.738 & 2.094 & 0.830 & 0.870 & 83.000 & 87.000 \\
\hline \multirow[t]{5}{*}{4} & Blank & 18.124 & 18.124 & - & - & - & - \\
\hline & 2 & 6.041 & 5.437 & 0.666 & 0.700 & 66.666 & 70.000 \\
\hline & 4 & 4.954 & 4.591 & 0.726 & 0.746 & 72.666 & 74.666 \\
\hline & 8 & 3.987 & 3.624 & 0.780 & 0.800 & 78.000 & 80.000 \\
\hline & 12 & 3.383 & 3.020 & 0.813 & 0.833 & 81.333 & 83.333 \\
\hline \multirow[t]{5}{*}{5} & Blank & 24.166 & 24.166 & - & - & - & - \\
\hline & 2 & 8.409 & 8.023 & 0.652 & 0.668 & 65.200 & 66.800 \\
\hline & 4 & 7.346 & 6.766 & 0.696 & 0.720 & 69.600 & 72.000 \\
\hline & 8 & 6.766 & 5.799 & 0.720 & 0.760 & 72.000 & 76.000 \\
\hline & 12 & 5.123 & 4.833 & 0.788 & 0.800 & 78.000 & 80.000 \\
\hline \multirow[t]{5}{*}{10} & Blank & 42.291 & 42.291 & - & - & - & - \\
\hline & 2 & 1.691 & 14.499 & 0.600 & 0.657 & 60.000 & 65.714 \\
\hline & 4 & 1.353 & 12.083 & 0.680 & 0.714 & 68.000 & 71.428 \\
\hline & 8 & 1.208 & 10.633 & 0.714 & 0.748 & 71.428 & 74.857 \\
\hline & 12 & 0.966 & 8.699 & 0.771 & 0.794 & 77.142 & 79.428 \\
\hline
\end{tabular}


Table 3: Gravimetric parameters for $1 \mathrm{~h}$ immersion time at different temperatures.

\begin{tabular}{|c|c|c|c|c|c|c|c|}
\hline \multirow{2}{*}{$\begin{array}{l}\text { Temperature } \\
\text { (K) }\end{array}$} & \multirow{2}{*}{$\begin{array}{c}\text { Concentration } \\
\left(\mathrm{g} \mathrm{l}^{-1}\right)\end{array}$} & \multicolumn{2}{|c|}{$\left(v_{\text {corr }}\right)^{-4}(\mathrm{mpy})$} & \multicolumn{2}{|c|}{$\begin{array}{c}\text { Surface coverage } \\
\qquad(\theta)\end{array}$} & \multicolumn{2}{|c|}{$\begin{array}{l}\text { Protection efficiency } \\
\qquad\left(\eta_{\mathrm{w}}\right)\end{array}$} \\
\hline & & EEMAS & WEMAS & EEMAS & WEMAS & EEMAS & WEMAS \\
\hline \multirow[t]{5}{*}{303} & Blank & 8.699 & 8.699 & & & & \\
\hline & 2 & 2.416 & 1.933 & 0.722 & 0.777 & 72.222 & 77.777 \\
\hline & 4 & 1.933 & 1.449 & 0.777 & 0.833 & 77.777 & 83.333 \\
\hline & 8 & 1.449 & 0.966 & 0.833 & 0.888 & 83.333 & 88.888 \\
\hline & 12 & 0.966 & 0.483 & 0.888 & 0.944 & 88.888 & 94.444 \\
\hline \multirow[t]{5}{*}{308} & Blank & 9.666 & 9.666 & - & - & - & - \\
\hline & 2 & 3.383 & 2.416 & 0.650 & 0.750 & 65.000 & 75.000 \\
\hline & 4 & 2.899 & 1.933 & 0.700 & 0.800 & 70.000 & 80.000 \\
\hline & 8 & 2.416 & 1.449 & 0.750 & 0.850 & 75.000 & 85.000 \\
\hline & 12 & 1.933 & 0.966 & 0.800 & 0.900 & 80.000 & 90.000 \\
\hline \multirow[t]{5}{*}{313} & Blank & 10.633 & 10.633 & - & - & - & - \\
\hline & 2 & 3.866 & 2.899 & 0.636 & 0.727 & 63.636 & 72.727 \\
\hline & 4 & 3.383 & 2.416 & 0.681 & 0.772 & 68.181 & 77.272 \\
\hline & 8 & 2.899 & 1.933 & 0.727 & 0.818 & 72.727 & 81.818 \\
\hline & 12 & 2.416 & 1.449 & 0.772 & 0.863 & 77.272 & 86.363 \\
\hline \multirow[t]{5}{*}{318} & Blank & 12.083 & 12.083 & - & - & - & - \\
\hline & 2 & 4.833 & 3.383 & 0.600 & 0.720 & 60.000 & 72.000 \\
\hline & 4 & 4.349 & 2.899 & 0.640 & 0.760 & 64.000 & 76.000 \\
\hline & 8 & 3.866 & 2.416 & 0.680 & 0.800 & 68.000 & 80.000 \\
\hline & 12 & 3.383 & 1.933 & 0.720 & 0.840 & 72.000 & 84.000 \\
\hline \multirow[t]{5}{*}{323} & Blank & 13.049 & 13.049 & - & - & - & - \\
\hline & 2 & 5.316 & 3.866 & 0.592 & 0.703 & 59.259 & 70.370 \\
\hline & 4 & 4.833 & 3.383 & 0.629 & 0.740 & 62.962 & 74.074 \\
\hline & 8 & 4.349 & 2.899 & 0.666 & 0.777 & 66.666 & 77.777 \\
\hline & 12 & 3.866 & 2.416 & 0.703 & 0.814 & 70.370 & 81.481 \\
\hline
\end{tabular}

Activation energy was calculated from the Arrhenius relation, i.e., plot of $\ln v_{\text {corr }}$ vs $1000 /$ T (Figure 1). ${ }^{26}$ Both activation entropy and enthalpy $\left(\Delta S^{*}\right.$ and $\Delta H^{*}$ ) were determined from transition state diagram (Figure 2), ${ }^{27}$ i.e., plot of $\ln v_{\text {corr }}$ vs $1000 / T$.

Table 4 shows that the values for corrosion inhibition process are higher compared to $0.5 \mathrm{M} \mathrm{HCl}$ solution, which indicates that the energy barrier influencing the corrosion process enhances in the presence of plant extracts. Positive sign of $\Delta H^{*}$ values without and with the addition of the plant extracts showed the endothermic nature of the aluminium corrosion process. Values of $\Delta S^{*}$ in the positive side are an indication of enhancement in disorderness of the system. 


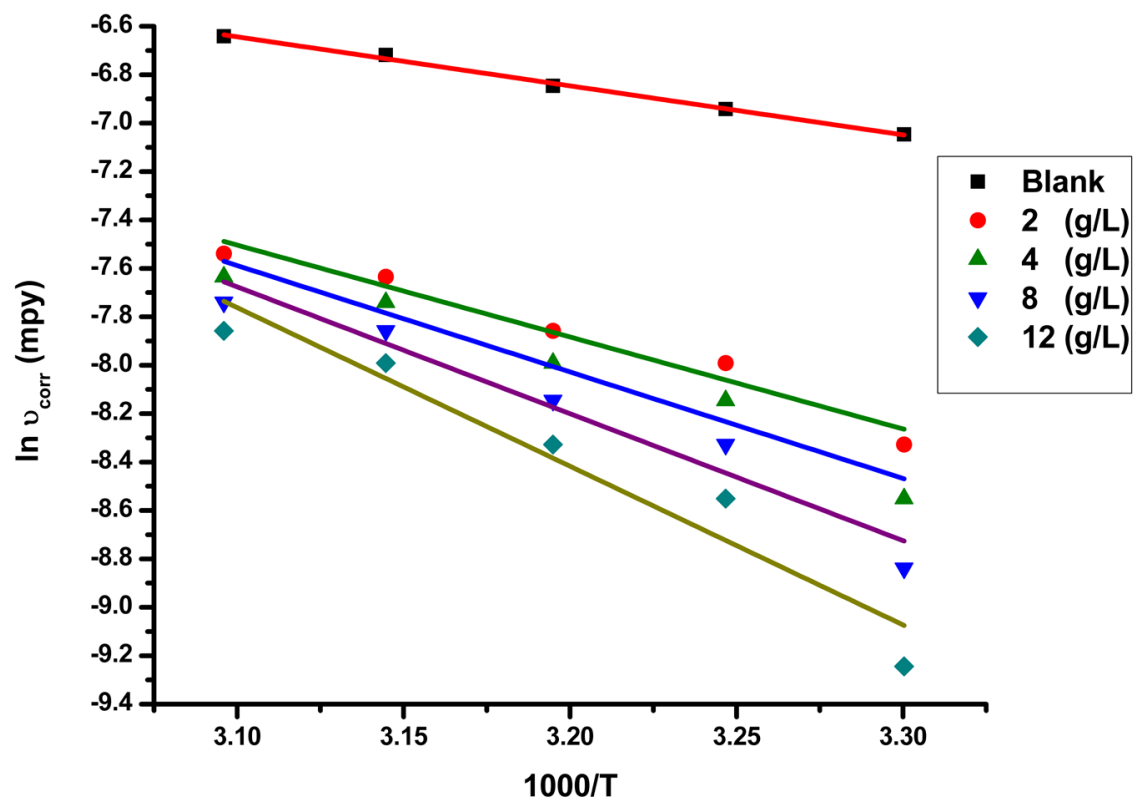

(a)

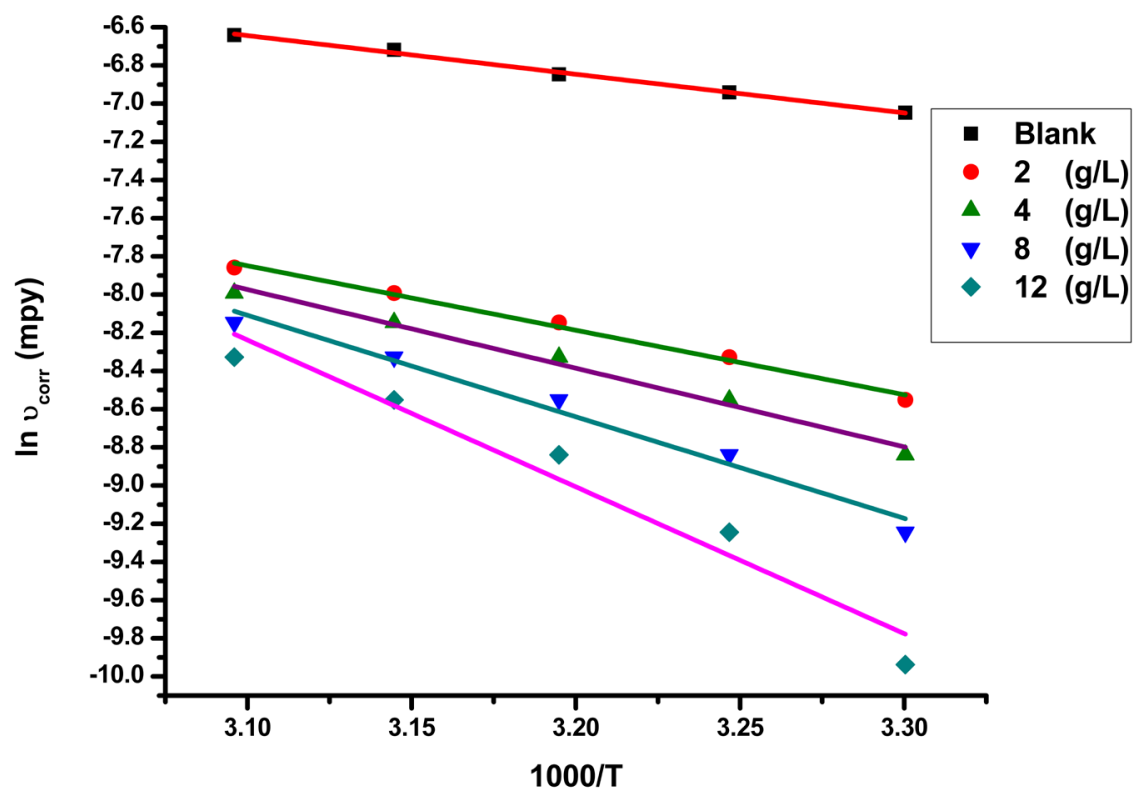

(b)

Figure 1: Arrhenius plots of experiment (a) without and with of EEMAS, (b) without and with of WEMAS. 


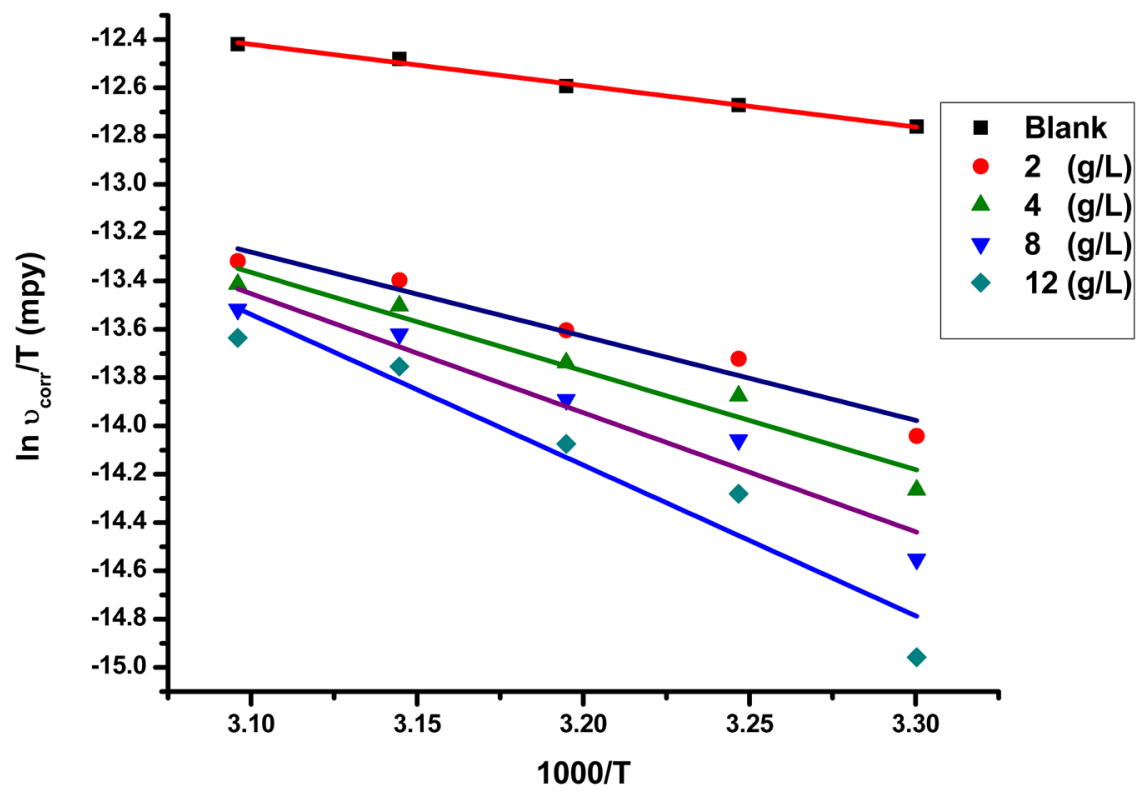

(a)

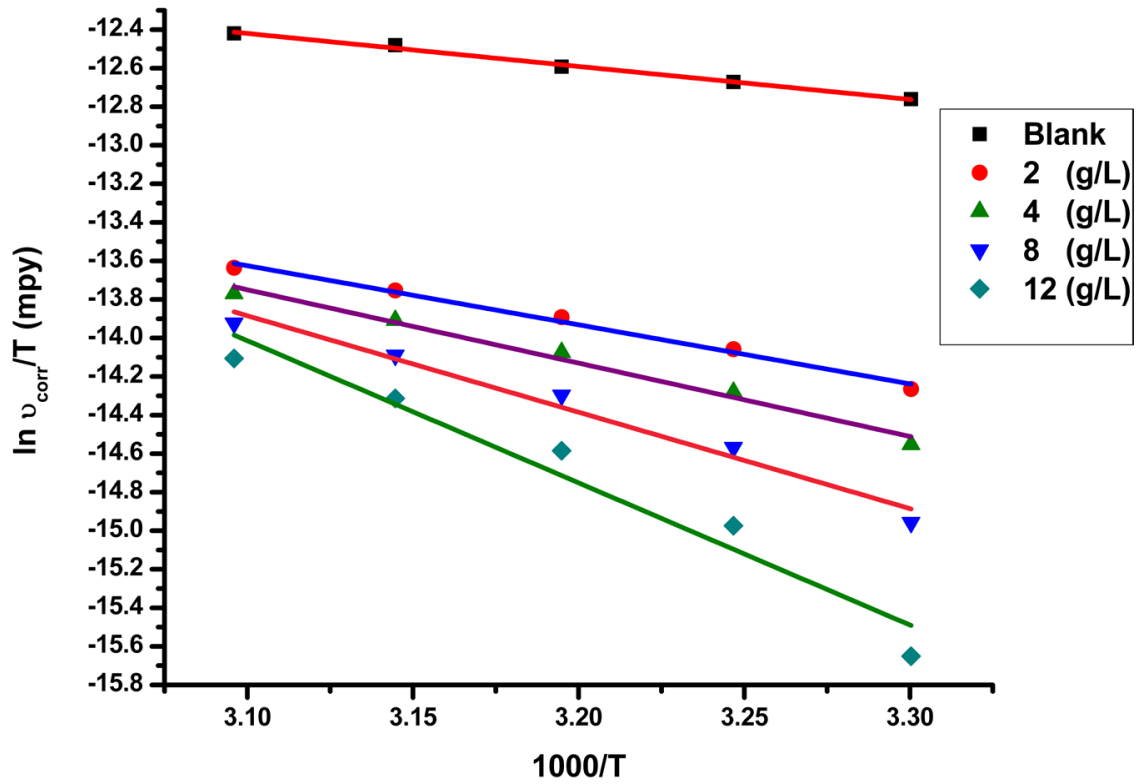

(b)

Figure 2: Transition state plots of experiment (a) without and with of EEMAS, (b) without and with of WEMAS. 
Table 4: Activation parameters.

\begin{tabular}{ccccc}
\hline Inhibitor & Concentration $\left(\mathrm{g} \mathrm{l}^{-1}\right)$ & $\mathrm{Ea}^{*}\left(\mathrm{~kJ} \mathrm{~mol}^{-1}\right)$ & $\Delta \mathrm{H}^{*}\left(\mathrm{~kJ} \mathrm{~mol}^{-1}\right)$ & $\Delta \mathrm{S}^{*}\left(\mathrm{~J} \mathrm{~mol}^{-1} \mathrm{~K}^{-1}\right)$ \\
\hline \multirow{2}{*}{ EEMAS } & Blank & 16.830 & 14.230 & -313.901 \\
& 2 & 31.562 & 28.962 & -275.385 \\
& 4 & 36.545 & 33.944 & -260.641 \\
& 8 & 43.574 & 40.974 & -239.580 \\
& 12 & 54.478 & 51.878 & -206.490 \\
WEMAS & Blank & 16.830 & 14.230 & -313.901 \\
& 2 & 28.084 & 25.483 & -289.036 \\
& 4 & 34.250 & 31.650 & -270.954 \\
& 8 & 44.194 & 41.593 & -241.253 \\
& 12 & 63.926 & 61.325 & -181.159 \\
\hline
\end{tabular}

Thermodynamic parameters of interaction between the surface of the metal and constituents of plant products can be represented by adsorption isotherm models and in the present study, weight loss technique data were fitted into different adsorption models in order to understand the nature of adsorption process. The best fit was observed in the Langmuir adsorption model, i.e., plot of $\mathrm{C} / \theta$ against $\mathrm{C}$, shown in Figure 3.28

In addition, $K_{a d s}$ values were also calculated from this plot and the resulting values were used in the determination of free energy of adsorption $\left(\Delta G_{a d s}^{\circ}\right)$ by employing the following equation:

$$
\Delta G_{a d s}^{\circ}=-2.303 R T \log \left(K_{a d s} C_{H_{2} O}\right)
$$

where $C_{\mathrm{H}_{2} \mathrm{O}}$ is the water concentration in solution, which equals to $1000 \mathrm{~g} \mathrm{l}^{-1}$. All calculated parameters are shortened in Table $5 . K_{a d s}$ is a binding capacity factor, with higher $K_{a d s}$ values indicating strong adsorption of plant molecules on active metal sites. These strongly adsorbed molecules block the direct contact of aqueous acid solution on the metal surfaces as a result corrosion rate of the metals decreases. This means that high protection efficiency is observed under existing conditions. The $\Delta G_{a d s}^{\circ}$ values around $-20 \mathrm{~kJ} \mathrm{~mol}^{-1}$ signify that the inhibitor (plant extract) molecules work by being physically adsorbed on the active metal surface. On the other hand, values around $-40 \mathrm{~kJ} \mathrm{~mol}^{-1}$ indicate that the inhibitor molecules work by being chemically adsorbed on the active metal surface. Hence, in all cases, the obtained values are around -35 to $-38 \mathrm{~kJ} \mathrm{~mol}^{-1}$, which indicates that the comprehensive adsorption of plant extract molecules on metal surfaces and negative sign confirms the spontaneous adsorption of plant extracts constituents on the metal surface. 


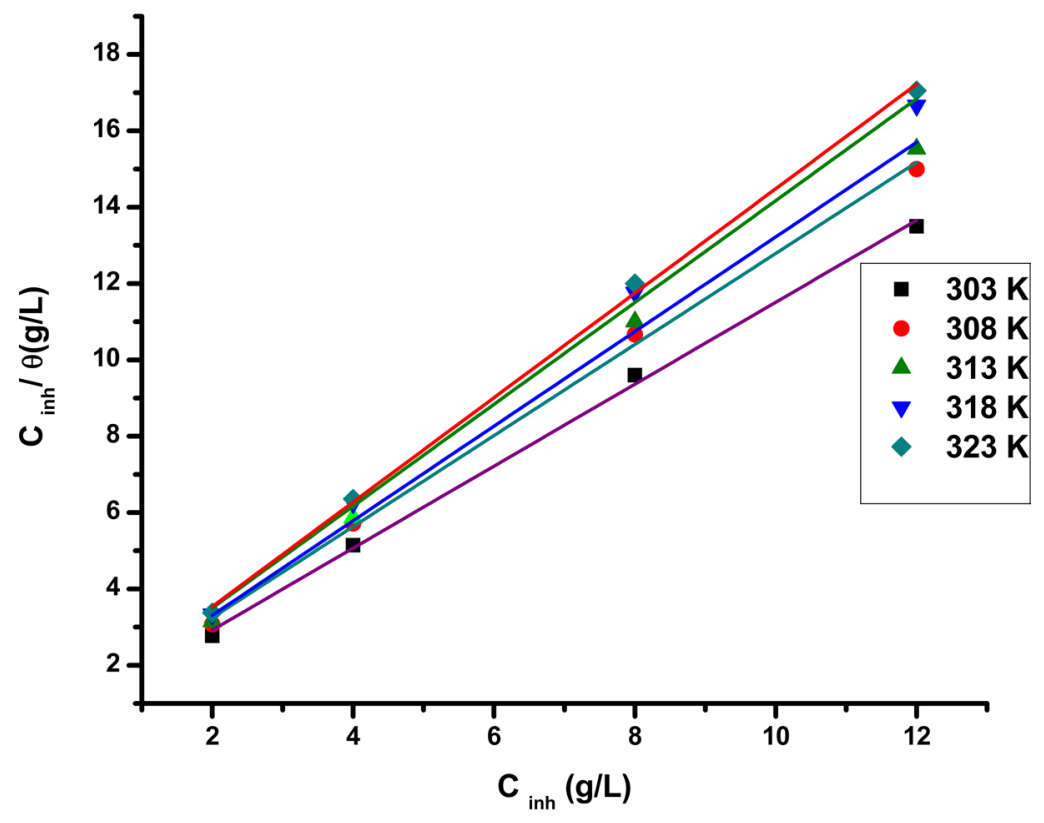

(a)

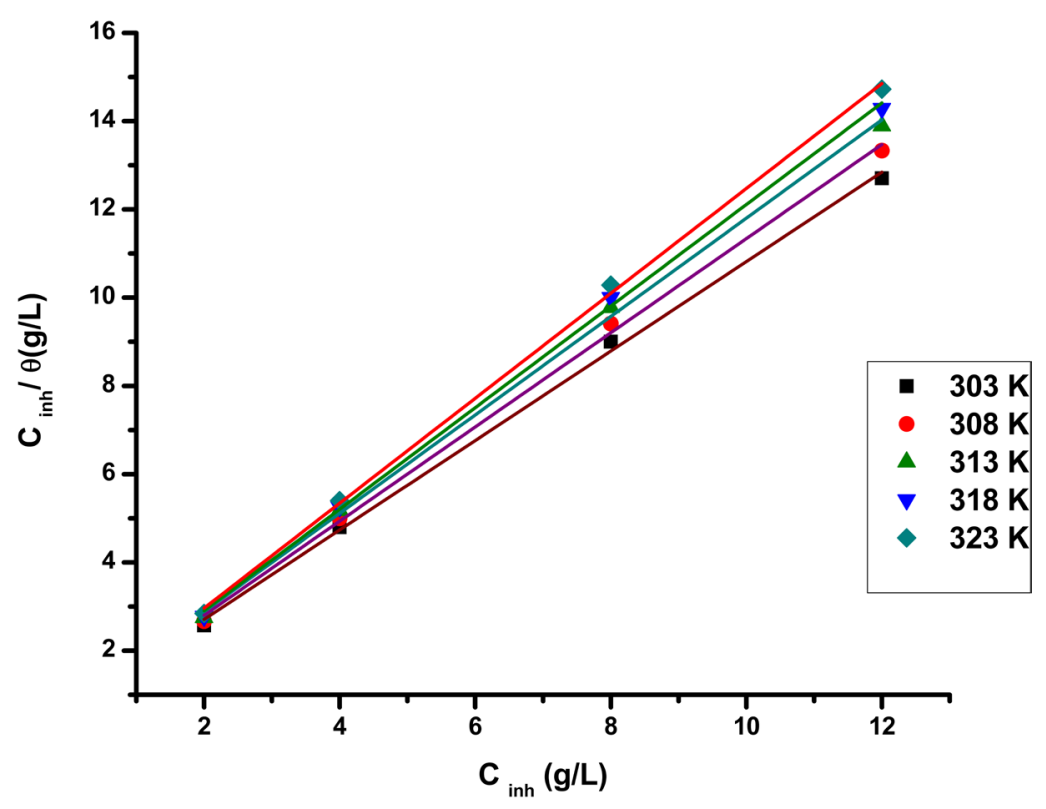

(b)

Figure 3: Langmuir adsorption model of experiment (a) without and with of EEMAS, (b) without and with of WEMAS. 
Table 5: Thermodynamic parameters.

\begin{tabular}{lccc}
\hline Inhibitor & Temp. $(\mathrm{K})$ & $\mathrm{K}_{\mathrm{ads}}\left(\mathrm{g} \mathrm{g}^{-1}\right)$ & $\Delta \mathrm{G}^{\mathrm{o}}$ ads $\left(\mathrm{kJ} \mathrm{mol}^{-1}\right)$ \\
\hline EEMAS & 303 & 1288.925 & -35.449 \\
& 308 & 1160.025 & -35.764 \\
& 313 & 1203.224 & -36.439 \\
& 318 & 1198.207 & -37.010 \\
& 323 & 1246.416 & -37.698 \\
WEMAS & 303 & 1470.609 & -35.781 \\
& 308 & 1497.768 & -36.418 \\
& 313 & 1529.683 & -37.064 \\
& 318 & 1667.611 & -37.885 \\
& 323 & 1704.797 & -38.539 \\
\hline
\end{tabular}

\subsection{Tafel Studies}

Tafel studies were carried out for the present system and the cathodic and anodic polarisation curves (Tafel plots) for blank and four different concentrations of plant extracts in acid medium were presented in Figure 4. The percentage inhibition efficiency $\left(\eta_{\mathrm{p}}\right)$ was calculated from corrosion current density $\left(i_{\text {corr }}\right)$ values using the following relationship:

$$
\eta_{\mathrm{p}}=\left[1-\frac{i_{\text {corr }}^{\prime}}{i_{\text {corr }}}\right] \times 100
$$

where $i_{\text {corr }}^{\prime}=$ corrosion current densities in the presence of inhibitor, and $i_{\text {corr }}=$ corrosion current densities in the absence of inhibitor.

Various Tafel parameters were determined and the resulting parameters were listed in Table 6 . The introduction of plant extracts to the corrosive medium significantly hinders both the anodic and cathodic reaction at active metal surface sites when compared with blank solution (decreases in $i_{\text {corr }}$ values with an increase in the plant extracts amount are an indication of a decrease in corrosion rate), indicating a high degree of protection to the aluminium metal surface by constituents of plant extracts. As a result, the corrosion protection efficiency enhanced gradually and the aluminium corrosion rate (in mpy) decreased more rapidly, with the maximum corrosion protection efficiency is achieved at the highest concentration $\left(12 \mathrm{~g}^{-1}\right)$ of plant extracts. Plant inhibitors can be classified as an anodic or a cathodic type if the variation in the $E_{\text {corr }}$ values is more than $85 \mathrm{mV}^{29,30}$ In the present case, the maximum shift in $E_{\text {corr }}$ were $22 \mathrm{mV}$ (for EEMAS extract) and $78 \mathrm{mV}$ (WEMAS extract), which implies that the inhibitors work through a mixed mode of inhibition by retarding both anodic dissolution and cathodic evolution reactions at active 


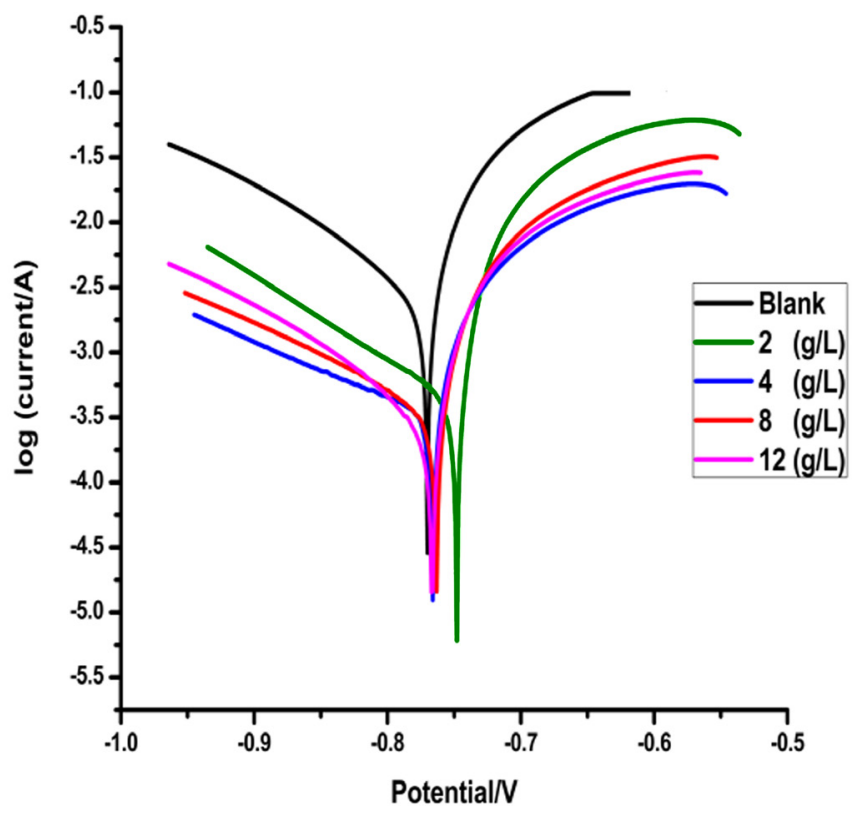

(a)

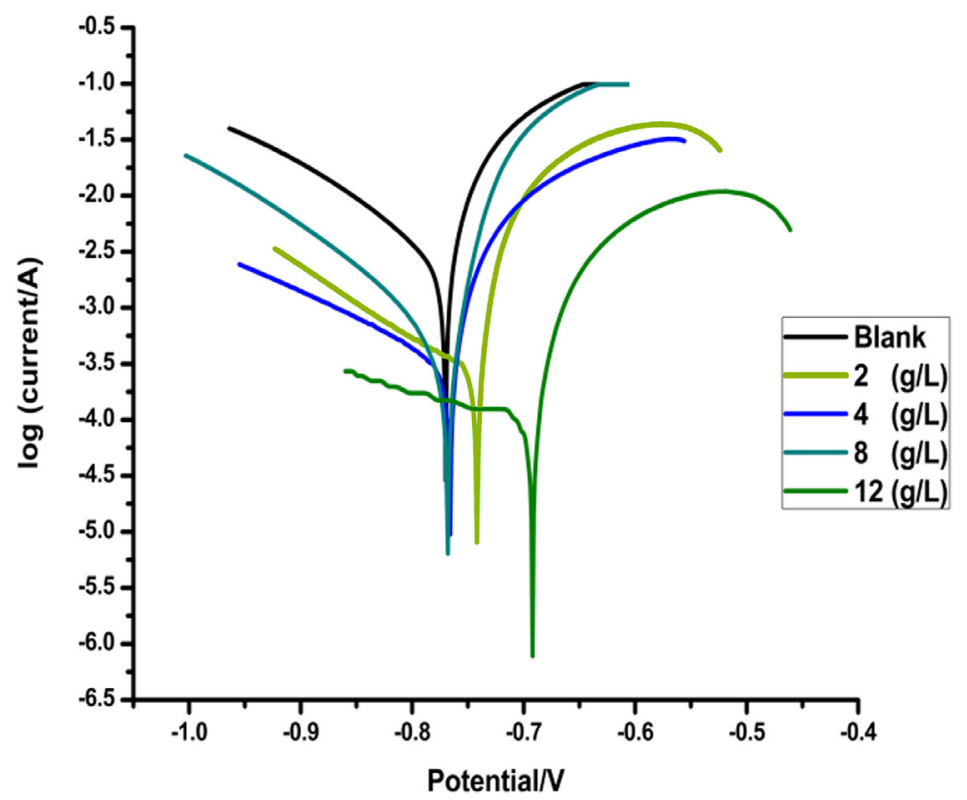

(b)

Figure 4: Tafel plots of experiment (a) without and with of EEMAS, (b) without and with of WEMAS. 
aluminium metal sites. In addition, increasing plant extract concentration in the examined solution did not notably modify either the anodic or cathodic Tafel slope values in any particular direction, indicating that the presence of inhibitors in test solution does not alter the corrosion process mechanism, but acts as an adsorption inhibitor which reduces the excessive metal dissolution in corrosive system.

Table 6: Tafel parameters.

\begin{tabular}{llccccc}
\hline Inhibitor & $\begin{array}{c}\text { Concentration } \\
\left(\mathrm{g} \mathrm{l}^{-1}\right)\end{array}$ & $\begin{array}{c}\mathrm{E}_{\text {corr }} \\
(\mathrm{mV})\end{array}$ & $\begin{array}{c}i_{\text {corr }} \times 10^{-3} \\
(\mathrm{~A})\end{array}$ & $\begin{array}{c}\beta \mathrm{c} \\
\left(\mathrm{V} \mathrm{dec}^{-1}\right)\end{array}$ & $\begin{array}{c}\beta \mathrm{a} \\
\left(\mathrm{V} \mathrm{dec}^{-1}\right)\end{array}$ & $\eta_{\mathrm{p}}$ \\
\hline EEMAS & Blank & -770 & 8.916 & 6.679 & 6.031 & - \\
& 2 & -748 & 2.197 & 6.462 & 6.131 & 75.358 \\
& 4 & -766 & 1.886 & 4.238 & 6.040 & 78.847 \\
& 8 & -763 & 1.589 & 5.061 & 6.413 & 82.178 \\
& 12 & -767 & 1.034 & 6.461 & 6.255 & 88.402 \\
WEMAS & Blank & -770 & 8.916 & 6.679 & 6.031 & - \\
& 2 & -742 & 1.636 & 6.345 & 5.990 & 81.650 \\
& 4 & -766 & 1.553 & 4.830 & 6.456 & 82.581 \\
& 8 & -768 & 0.988 & 7.731 & 7.982 & 88.909 \\
& 12 & -692 & 0.648 & 2.436 & 6.550 & 92.727 \\
\hline
\end{tabular}

\subsection{AC Impedance Spectroscopy Analysis}

Impedance technique is one of the widely used techniques for corrosion monitoring, as it offers more information on the capacitive and resistive behaviour of the aluminium/acid interface. The corrosion behaviour of aluminium in acid medium, without and with different concentrations of plant extracts, was investigated using this technique. The Nyquist plots are shown in Figure 5. One can observe many similarities between different plots indicating that the addition of inhibitor reduced the corrosion rate without altering the other electrochemical characteristics of the test solution. The Z software (model; ZSimpwin 3.20) was used to determine the impedance parameters.

The electrical equivalent circuit $[\mathrm{R}(\mathrm{QR}(\mathrm{QR}))]$ fixed the superlative impedance records. From this circuit, charge transfer resistance $\left(R_{\mathrm{c}}\right)$, frequency $\left(f_{\max }\right)$, chi squared value $\left(\chi^{2}\right)$, double layer capacitance $\left(C_{\mathrm{dl}}\right)$ and CPE exponent $(n)$ values were determined. Protection efficiency $\left(\eta_{\mathrm{z}}\right)$ values were determined using the following relation: 


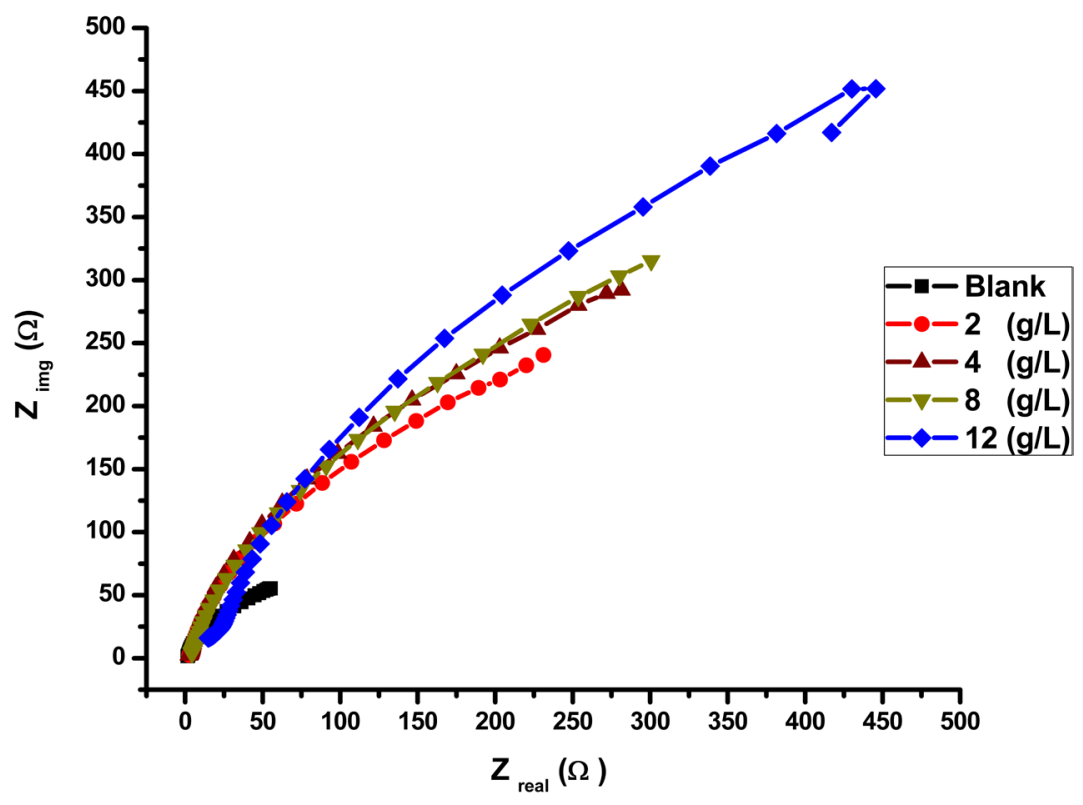

(a)

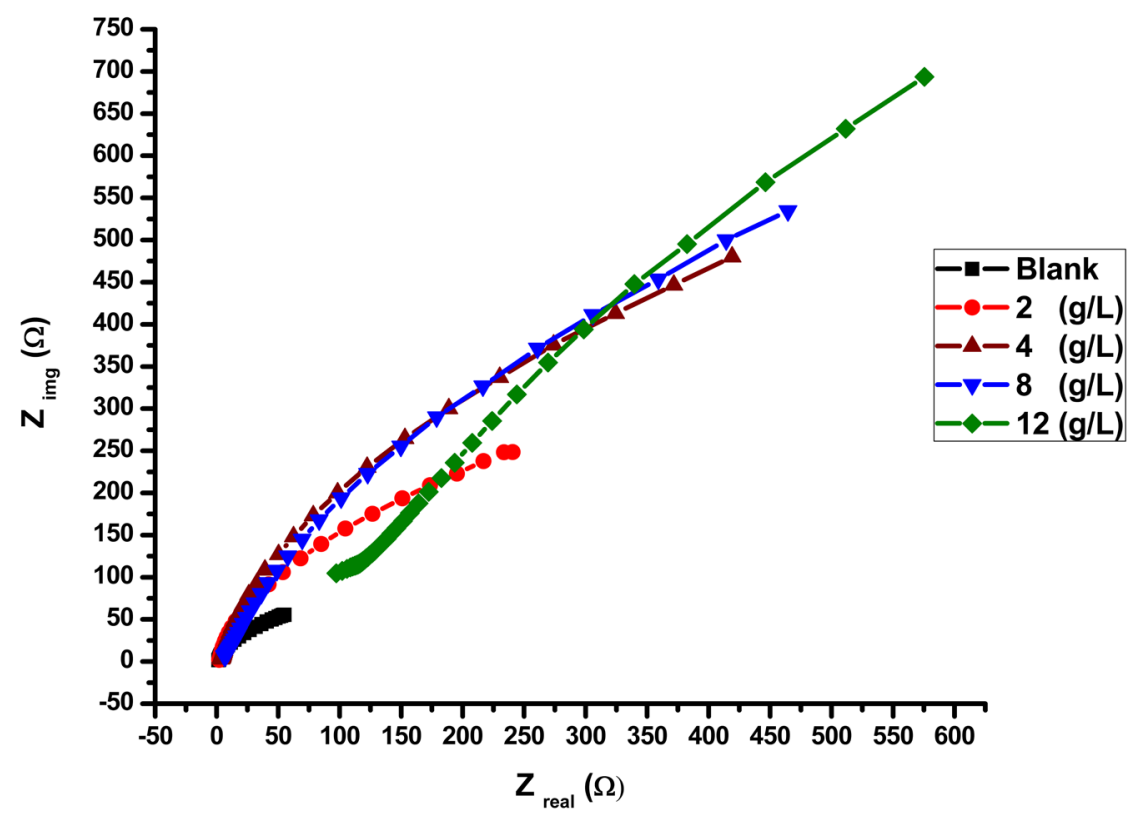

(b)

Figure 5: Nyquist plots of experiment (a) without and with of EEMAS, (b) without and with of WEMAS. 


$$
\eta_{\mathrm{z}}=\frac{R_{\mathrm{ct}(\mathrm{inh})}-R_{\mathrm{ct}}}{R_{\mathrm{ct}(\mathrm{inh})}} \times 100
$$

where $R_{\mathrm{ct}(\mathrm{inh})}$ and $R_{\mathrm{ct}}$ are the resistance in the presence of plant extract and resistance in the absence of plant extract, respectively.

The parameters obtained from impedance spectra are listed in Table 7. The charge transfer resistance $\left(R_{\mathrm{ct}}\right)$ values appeared to be enhanced with the introduction of plant extracts, indicating the formation of a tenacious layer on the surface of aluminium metal which makes a barrier for mass and charge-transfer, while, the lower $C_{\mathrm{dl}}$ values in the presence of plant extracts indicate the existence of an efficient passive layer on aluminium surface, and become stronger with increasing plant extract concentration, which in turn hinder aluminium metal active surface area that is accessible for the direct acid attack. The obtained $\chi^{2}$ (indicates the quality of electrical circuit fit) values signify a better fitting to the proposed circuit.

Table 7: Electrochemical impedance parameters.

\begin{tabular}{llllllc}
\hline Inhibitor & Concentration $\left(\mathrm{g}^{-1}\right)$ & \multicolumn{1}{c}{$\mathrm{n}$} & \multicolumn{1}{c}{$R_{\mathrm{ct}} \Omega$} & \multicolumn{1}{c}{$C_{\mathrm{dl}}(\mu \mathrm{F})$} & \multicolumn{1}{c}{$\chi^{2}$} & $\eta_{\mathrm{z}}$ \\
\hline \multirow{2}{*}{ EEMAS } & Blank & 1 & 55.94 & 291.355 & 0.00147 & - \\
& 2 & 0.9111 & 264.6 & 160.908 & 0.000447 & 78.858 \\
& 4 & 0.9111 & 329.2 & 156.538 & 0.000764 & 83.007 \\
& 8 & 0.7398 & 356.9 & 174.965 & 0.0008406 & 84.326 \\
& 12 & 0.5501 & 490.6 & 86.784 & 0.005489 & 88.597 \\
WEMAS & Blank & 1 & 55.94 & 291.355 & 0.00147 & - \\
& 2 & 0.9399 & 267.2 & 159.342 & 0.0005154 & 79.064 \\
& 4 & 0.87 & 618.3 & 148.010 & 0.0004641 & 90.952 \\
& 8 & 0.7526 & 782.3 & 142.341 & 0.0007108 & 92.849 \\
& 12 & 0.9424 & 1245 & 108.389 & 0.0005245 & 95.506 \\
\hline
\end{tabular}

\subsection{FTIR Spectroscopy}

Figure 6 shows the broad bands around $3232 \mathrm{~cm}^{-1}$ for WEMAS and $3252 \mathrm{~cm}^{-1}$ for EEMAS, which confirms that the hydroxyl groups present in the plant extracts molecules. The presence of $\mathrm{C}=\mathrm{O}$ groups in the extract molecules was confirmed by the existence of bands in the region of $1602 \mathrm{~cm}^{-1}$ for WEMAS and $1613 \mathrm{~cm}^{-1}$ for EEMAS. Further, the presence of C-H stretching was also confirmed from the spectrum $\left(2894 \mathrm{~cm}^{-1}, 1438 \mathrm{~cm}^{-1}\right.$ and $1366 \mathrm{~cm}^{-1}$ for WEMAS, and $2925 \mathrm{~cm}^{-1}$, $1449 \mathrm{~cm}^{-1}$ and $1357 \mathrm{~cm}^{-1}$ for EEMAS). Appearance of bands at $1100 \mathrm{~cm}^{-1}$ in both extracts confirms the existence of a C-O bond. Bands around $2381 \mathrm{~cm}^{-1}$ (for WEMAS) and $2351 \mathrm{~cm}^{-1}$ (for EEMAS) indicates the presence of $\mathrm{O}-\mathrm{C}=\mathrm{O}$ groups in extracts. 


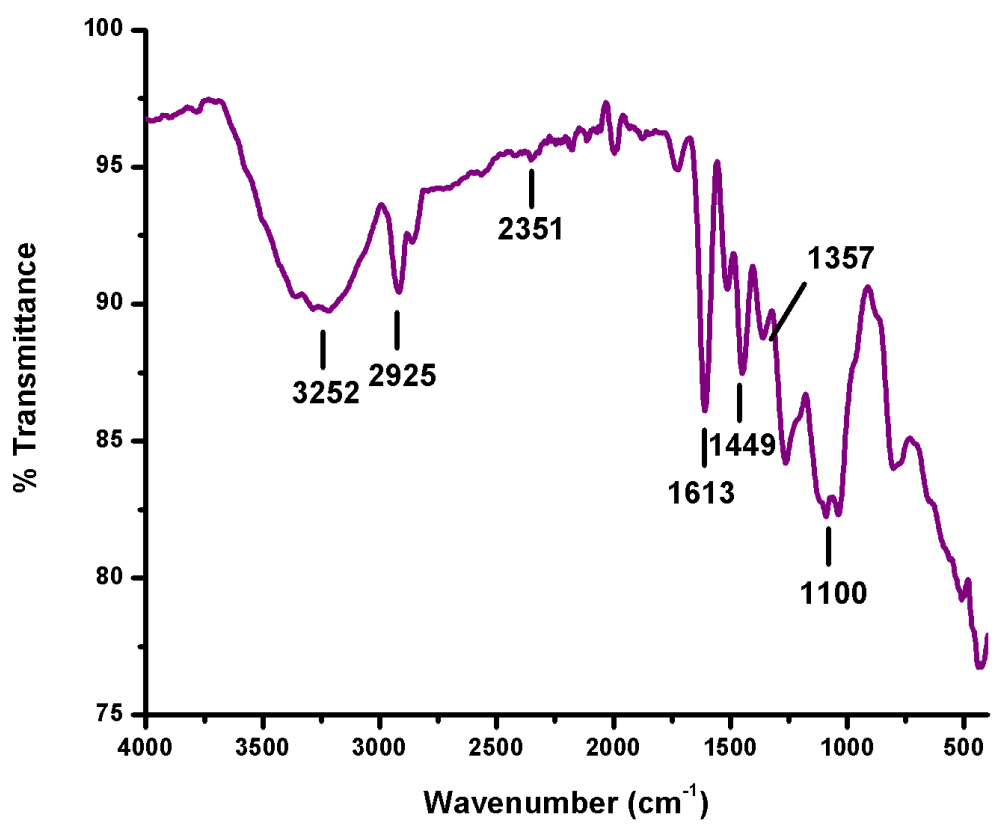

(a)

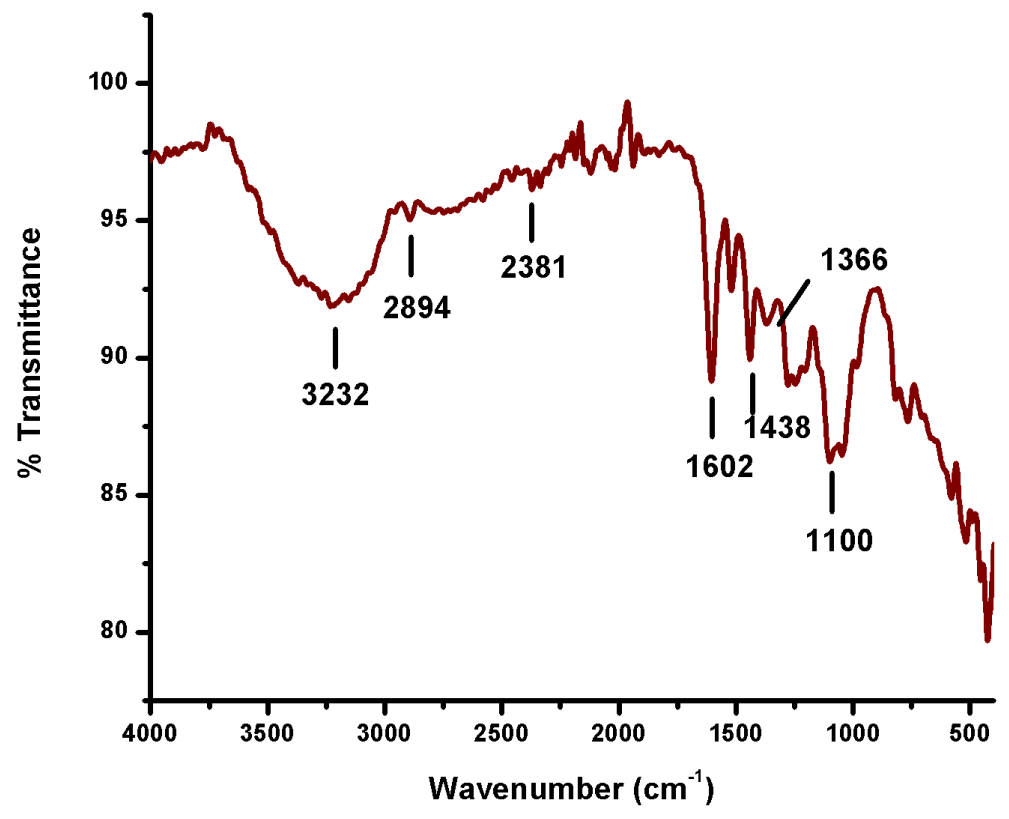

(b)

Figure 6: FTIR spectrum of (a) EEMAS and (b) WEMAS. 


\subsection{Surface Studies}

\subsubsection{SEM results}

The surface morphology of the aluminium specimen submerged in $0.5 \mathrm{M} \mathrm{HCl}$ solution without and with of plant extracts was analysed using SEM and resulted morphology are shown in Figure 7. From these figures, it is clear that multiple scratches on the aluminium metal surface in inhibiting free solution are due to a direct attack of chlorine ions from aggressive systems to active aluminium metal sites. Whereas, smooth surface on the aluminium metal surface in inhibiting solution is due to adsorption of plant constituents on the aluminium metal surface, which prevents the attack of $\mathrm{Cl}^{-}$ions on the active sites of metal. Therefore, more surface area is occupied by plant constituents that are responsible for aluminium corrosion inhibition process.

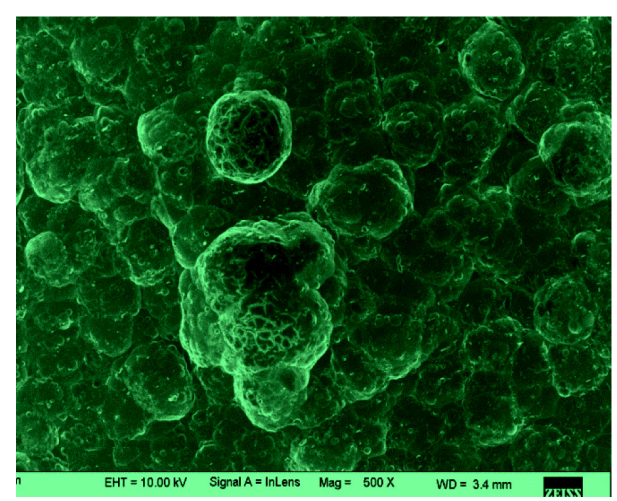

Without EEMAS

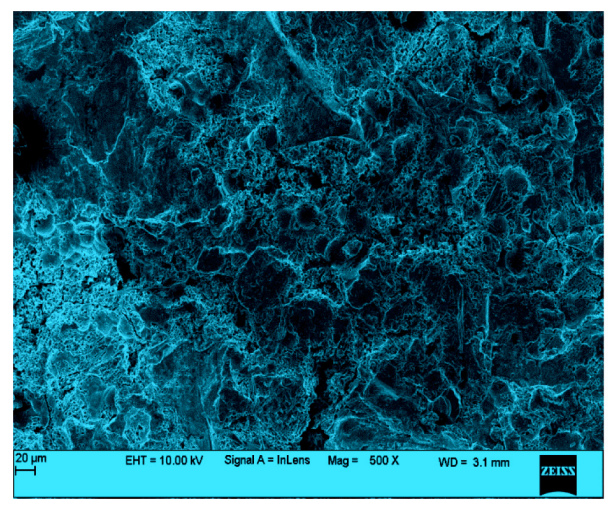

Without WEMAS

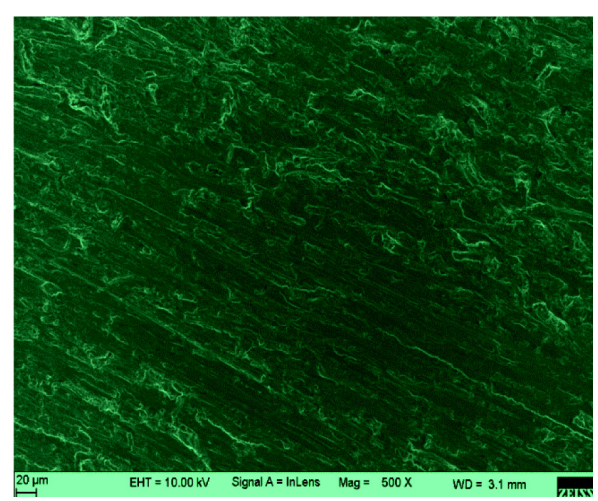

With EEMAS

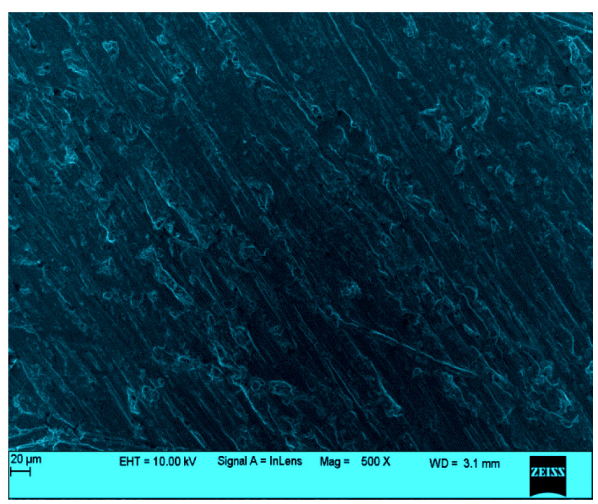

With WEMAS

Figure 7: SEM images without and with plant product. 


\subsubsection{AFM results}

The decrease in roughness value (Table 8, Figure 8) in the presence of the inhibitors is evidence of corrosion inhibition action of inhibitory species on metal (aluminium) surface in a corrosive solution $(0.5 \mathrm{M} \mathrm{HCl})$. A greater decrease in roughness value (both average and root mean square roughness) in the presence of WEMAS is an indication of superior inhibitory activity over other inhibitor EEMAS. AFM results obey the chemical and electrochemical results.

Table 8: AFM results.

\begin{tabular}{lccc}
\hline Inhibitor & Concentration $\left(\mathrm{g}^{-1}\right)$ & Average roughness $\left(\mathrm{S}_{\mathrm{a}}\right)$ & Root mean square roughness $\left(\mathrm{S}_{\mathrm{q}}\right)$ \\
\hline \multirow{2}{*}{ EEMAS } & 0 & $473.1 \mathrm{~nm}$ & $614.31 \mathrm{~nm}$ \\
& 12 & $276.39 \mathrm{~nm}$ & $379.2 \mathrm{~nm}$ \\
\multirow{2}{*}{ WEMAS } & 0 & $666.68 \mathrm{~nm}$ & $18.66 \mathrm{~nm}$ \\
& 12 & $100.8 \mathrm{~nm}$ & $132.4 \mathrm{~nm}$ \\
\hline
\end{tabular}
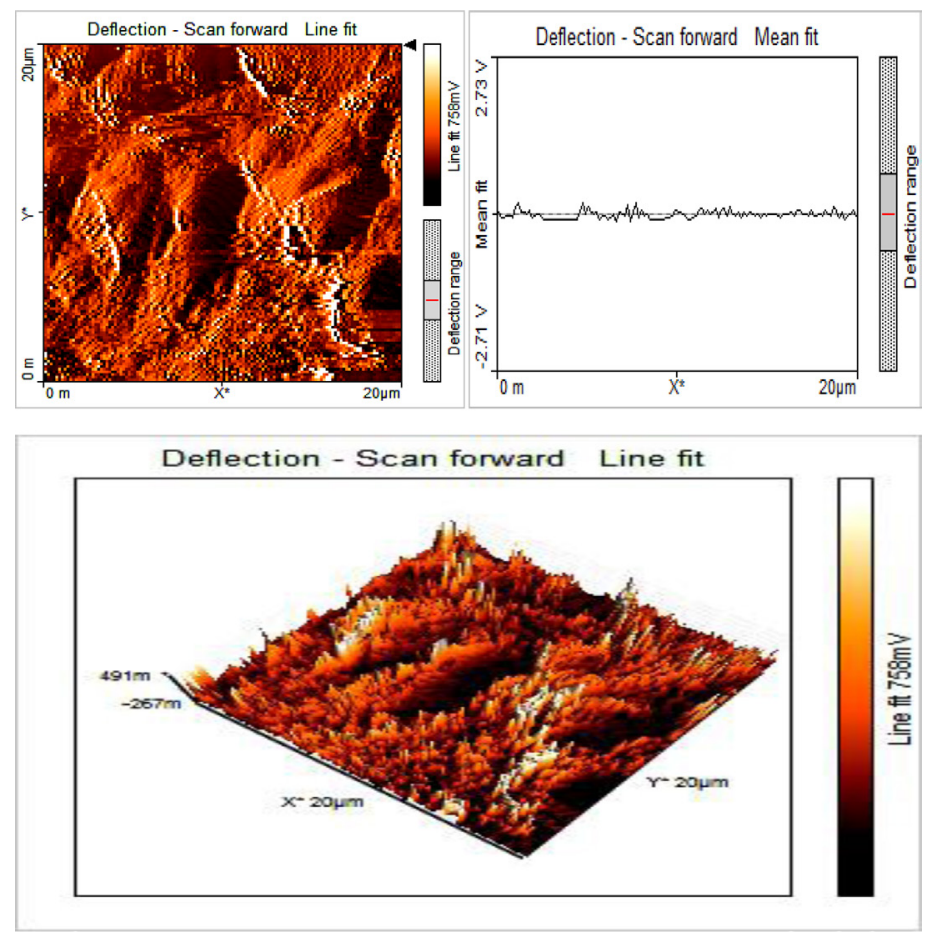

(a)

Figure 8: AFM images of (a) without EEMAS, (b) with EEMAS, (c) without WEMAS, and (d) with WEMAS (continued on next page). 

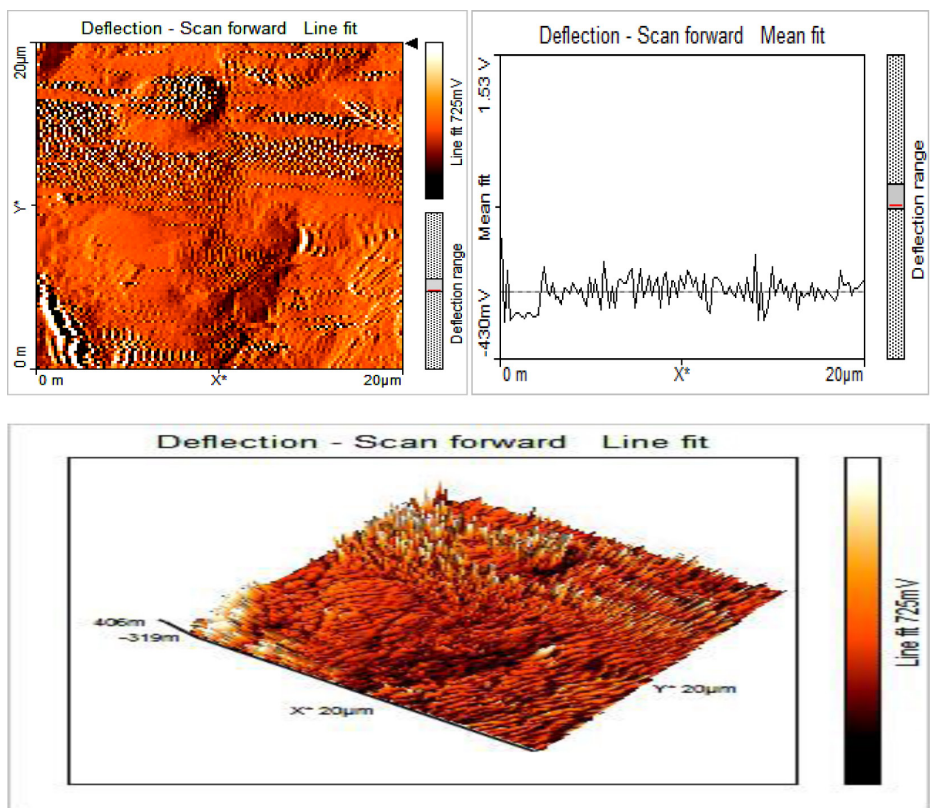

(b)
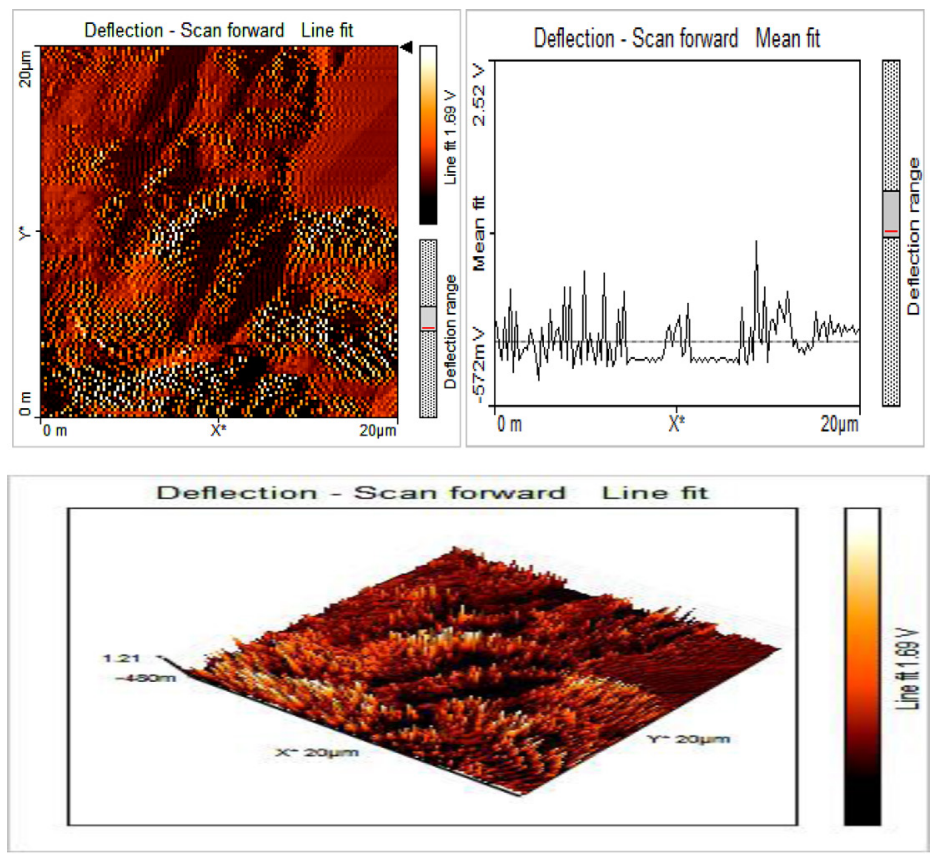

(c)

Figure 8: (Continued). 

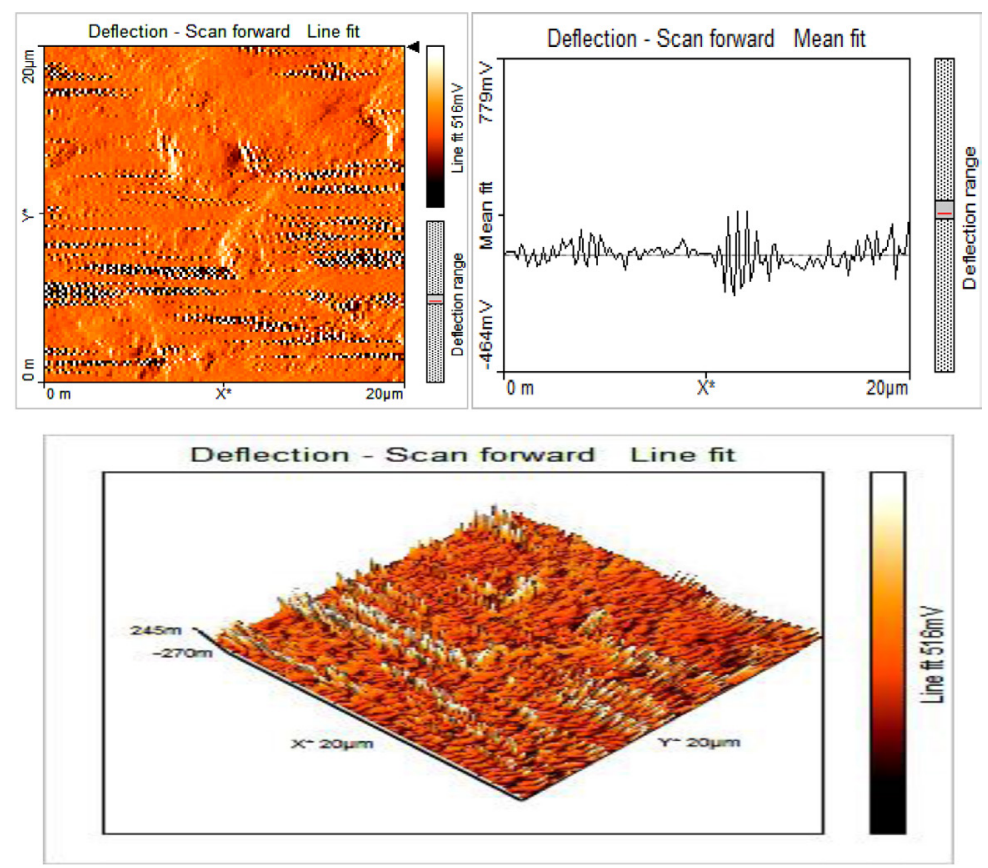

(d)

Figure 8: (Continued).

\section{CONCLUSION}

The present study shows the corrosion inhibition behaviour of mature arecanut seed extracts on the aluminium metal surface in $0.5 \mathrm{M} \mathrm{HCl}$ environment. The results obtained from mass loss (gravimetric) technique confirmed that the inhibition process takes place through adsorption of plant extracts constituents on the electrode surface, which were perfectively fitted to Langmuir adsorption mode. Tafel studies clearly indicated the mixed mode inhibition behaviour of plant extracts. AC impedance spectroscopy studies revealed that the inhibition of aluminium corrosion by plant extracts may be due to the presence of active thin passive layer. Further, SEM surface images fully support the results of weight loss and electrochemical studies. Among the EEMAS and WEMAS inhibitors, in all cases WEMAS showed better inhibition property over EEMAS due to its high electron density, this favours the higher adsorption of plant constituents on metal surfaces which effectively blocks the movement of $\mathrm{Cl}^{-}$ions towards active metal sites. The lower electron density in EEMAS constituents justified the lesser inhibition performance for aluminium metal in the aggressive $\mathrm{HCl}$ environment as compared to WEMAS. Ethyl acetate is less polar compared to water and water will 
extract more polar molecules from mature arecanut seed compared to ethyl acetate. Hence, more molecules present in the water extract adsorb on metal surface forms a strong protective film that is responsible for the blocking the movement of corrosive ions on metal surface. Therefore, water extract gives high protection efficiency compared to extraction with ethyl acetate. Further, AFM results greatly support the high corrosion inhibition activity of WEMAS compared to EEMAS.

\section{ACKNOWLEDGEMENTS}

Authors are thankful to Dr. B. E. Kumaraswamy of Kuvempu University, India for providing an instrument (CHI660C) facility to carry out electrochemical studies. Authors are also thankful to the Department of Science and Technology, Promotion of University Research and Scientific Excellence (DST-PURSE) and University Science Instrumentation Centre (USIC) of Mangalore University for SEM and FTIR results. The funding for this research was provided by University Grant Commission - Special Assistance Program (UGC-SAP).

\section{REFERENCES}

1. Ameh, P. O. \& Eddy, N. O. (2014). Commiphora pedunculata gum as a green inhibitor for the corrosion of aluminium alloy in $0.1 \mathrm{M} \mathrm{HCl}$. Res. Chem. Intermed., 40, 2641-2649, https://doi.org/10.1007/s11164-0131117-0.

2. Afia, L. et al. (2012). Argan hulls extract: Green inhibitor of mild steel corrosion in $1 \mathrm{M} \mathrm{HCl}$ solution. Res. Chem. Intermed., 38, 1707-1717, https://doi.org/10.1007/s11164-012-0496-y.

3. Akin, M. et al. (2015). Juglans regia L. extract as green inhibitor for stainless steel and aluminium in acidic media. Res. Chem. Intermed., 41, 899-912, https://doi.org/10.1007/s11164-013-1241-x.

4. Ishwara Bhat, J. \& Alva, V. D. P. (2011). A study of aluminium corrosion inhibition in acid medium by an antiemitic drug. Trans. Indian. Inst. Met., 64, 377-384, https://doi.org/10.1007/s12666-011-0102-9.

5. Mehdaoui, R., Khelifa, A. \& Aaboubi, O. (2015). Inhibiting effect of some synthesized surfactants from petroleum oils on the corrosion of aluminium in hydrochloric acid solution. Res. Chem. Intermed., 41, 705-720, https://doi.org/10.1007/s11164-013-1222-0.

6. Okafor, P. C., Osabor, V. \& Ebenso, E. E. (2007). Ecofriendly corrosion inhibitors: Inhibitive action of ethanol extracts of Garcinia kola for the corrosion of aluminum in acidic medium. Pigm. Resin. Technol., 36, 299305, https://doi.org/10.1108/03699420710820414. 
7. Noor, E. A. (2009). Potential of aqueous extract of Hibiscus sabdariffa leaves for inhibiting the corrosion of aluminum in alkaline solutions. J. Appl. Electrochem., 39, 1465-1475, https://doi.org/10.1007/s10800009-9826-1.

8. Fouda, A. S., Mohamed, F. S. \& El-Sherbeni, M. W. (2016). Corrosion inhibition of aluminum-silicon alloy in hydrochloric acid solutions using carbamidic thioanhydride derivatives. J. Bio Tribo. Corros., 2, 11, https://doi.org/10.1007/s40735-016-0039-y.

9. Paul, S. \& Koley I. (2016). Corrosion inhibition of carbon steel in acidic environment by papaya seed as green inhibitor. J. Bio Tribo. Corros., 2, 6, https://doi.org/10.1007/s40735-016-0035-2.

10. Raghavendra, N. \& Ishwara Bhat, J. (2016). Green approach to inhibition of corrosion of aluminium in $0.5 \mathrm{M} \mathrm{HCl}$ medium by tender arecanut seed extract: Insight from gravimetric and electrochemical studies. Res. Chem. Intermed., 42, 6351-6372. https://doi.org/10.1007/s11164-016-2467-1

11. Raghavendra, N. \& Ishwara Bhat, J. (2016). Natural products for material protection: An interesting and efficacious anticorrosive property of dry arecanut seed extract at electrode (aluminium)-electrolyte (hydrochloric acid) interface. J. Bio Tribo. Corros., 2, 21. https://doi.org/10.1007/s40735016-0051-2.

12. Anupama, K. K. Shainy, K. M. \& Abraham, J. (2016). Excellent anticorrosion behavior of ruta graveolens extract (RGE) for mild steel in hydrochloric acid: Electro analytical studies on the effect of time, temperature, and inhibitor concentration. J. Bio Tribo. Corros., 2, 2, https://doi.org/10.1007/s40735-016-0032-5.

13. Gunasekaran, G. \& Chauhan, L. R. (2004). Eco friendly inhibitor for corrosion inhibition of mild steel in phosphoric acid medium. Electrochim. Acta, 49, 4387-4395, https://doi.org/10.1016/j.electacta.2004.04.030.

14. Abiola, O. K. \& James, A. O. (2010). The effects of aloe vera extract on corrosion and kinetics of corrosion process of zinc in $\mathrm{HCl}$ solution. Corr. Sci., 52, 661-664, https://doi.org/10.1016/j.corsci.2009.10.026.

15. El-Etre, A.Y. (2003). Inhibition of aluminum corrosion using Opuntia extract. Corr. Sci., 45, 2485-2495, https://doi.org/10.1016/S0010-938X(03) 00066-0.

16. Mathew, A. G. \& Govindarajan, V. S. (1964). Polyphenolic substances of arecanut: Changes during maturation and ripening. Phytochem., 3, 657665, https://doi.org/10.1016/S0031-9422(00)82963-5.

17. Wang, C. K. \& Lee, W. H (1996). Separation, characteristics, and biological activities of phenolics in Areca fruit. J. Agric. Food Chem., 44, 2014-2019. https://doi.org/10.1021/jf950611o. 
18. Wang, C. K., Lee, W. H. \& Peng, C. H. (1997). Contents of phenolics and alkaloids in Areca catechu Linn. during maturation. J. Agric. Food Chem., 45, 1185-1188, https://doi.org/10.1021/jf960547q.

19. Hu, C. W. \& Chao, M. R. (2012). Direct-acting DNA alkylating agents present in aqueous extracts of areca nut and its products. Chem. Res. Toxicol., 25, 2386-2392, https://doi.org/10.1021/tx300252r.

20. Hamsar, M. N. et al. (2011). Antioxidant activity and the effect of different parts of Areca catechu extracts on glutathione-S-transferase activity in vitro. Free Rad. Antiox., 1, 28-33, https://doi.org/10.5530/ax.2011.1.6.

21. Zhang, W. M. et al. (2011). The chemical composition and phenolic antioxidants of areca (Areca catechu L.) seeds. Paper presented in the International Conference on Agricultural and Biosystems Engineering Advances in Biomedical Engineering, 1(2), 16-22.

22. Zhang, W-M. et al. (2009). Antioxidant activities of extracts from areca (Arecacatectu L.) flower, husk and seed. Afr. J. Biotechnol., 8, 3887-3892, https://doi.org/10.5897/AJB09.411.

23. Nayar, A. (1997). The metals databook. New Delhi: Tata McGraw-Hill.

24. Li, X. H. et al. (2009). Adsorption and inhibition effect of 6-benzylaminopurine on cold rolled steel in $1.0 \mathrm{M} \mathrm{HCl}$. Electrochim. Acta, 54, 4089-4098, https://doi.org/10.1016/j.electacta.2009.02.084.

25. Ostovari, A. et al. (2009). Corrosion inhibition of mild steel in $1 \mathrm{M} \mathrm{HCl}$ solution by henna extract: A comparative study of the inhibition by henna and its constituents (lawsone, gallic acid, $\alpha$-d-glucose and tannic acid). Corr. Sci., 5, 1935-1949, https://doi.org/10.1016/j.corsci.2009.05.024.

26. Kumar, S. et al. (2013). Experimental and quantum chemical studies on corrosion inhibition effect of synthesized organic compounds on N80 steel in hydrochloric acid. Ind. Eng. Chem. Res., 52, 14019-14029, https://doi. org/10.1021/ie401308v.

27. Tebbji, K. et al. (2007). The effect of some lactones as inhibitors for the corrosion of mild steel in 1M hydrochloric acid. Mater. Chem. Phys., 106, 260-267. https://doi.org/10.1016/j.matchemphys.2007.05.046.

28. Dhar, H. P., Conway, B. E. \& Joshi, K. M. (1973). On the form of adsorption isotherms for substitutional adsorption of molecules of different sizes. Electrochim. Acta, 18, 789-798, https://doi.org/10.1016/00134686(73)85030-3.

29. Shainy, K. M. et al. (2016). Surface interaction and corrosion inhibition of mild steel in hydrochloric acid using pyoverdine, an eco-friendly biomolecule. J. Bio Tribo. Corros., 2, 20, https://doi.org/10.1007/s40735-0160050-3.

30. Kuruvilla, M., John, S. \& Joseph, A. (2016). Electroanalytical studies on the interaction of 1-Serine-based Schiff base, HHDMP, with copper in sulphuric acid. J. Bio Tribo. Corros., 2, 19, https://doi.org/10.1007/s40735-016-0049-9. 